\title{
The effect of glibenclamide on insulin secretion at normal glucose concentrations
}

\author{
Axel Riefflin • Usha Ayyagari • Susan E. Manley • \\ Rury R. Holman • Jonathan C. Levy
}

Received: 30 April 2014 / Accepted: 4 September 2014 / Published online: 9 October 2014

(C) Springer-Verlag Berlin Heidelberg 2014

\begin{abstract}
Aims/hypothesis The aim of this study was to investigate the incremental and proportional effect of a sulfonylurea on insulin secretion rates at low, elevated and high blood glucose, using parallel groups with ascending or descending glucose steps to minimise potential biases of a single stepped clamp order.

Methods Following 14 days on placebo or glibenclamide ( $2.5 \mathrm{mg}$ ) tablets twice daily, separated by 14 days washout, 19 type 2 diabetic patients had ascending or descending threestep hyperinsulinaemic glucose clamps at 4,8 and $12 \mathrm{mmol} / \mathrm{l}$. C-peptide secretion was estimated by two-compartment C-peptide deconvolution.

Results Patients in the ascending glucose steps group $(n=10)$ had mean (SD) age of $60.3(6.5)$ years, BMI of $29.8(4.9) \mathrm{kg} / \mathrm{m}^{2}$
\end{abstract}

\footnotetext{
A. Riefflin

GMP Husby, Husby, Germany

U. Ayyagari · J. C. Levy $(\bowtie)$

Oxford Centre for Diabetes, Endocrinology and Metabolism,

University of Oxford, Churchill Hospital, Old Road, Headington,

Oxford OX3 7LJ, UK

e-mail: jonathan.levy@ocdem.ox.ac.uk

S. E. Manley

Divisional of Medical Sciences, University of Birmingham,

Birmingham, UK

R. R. Holman

Diabetes Trials Unit, Oxford Centre for Diabetes, Endocrinology and

Metabolism, University of Oxford, Churchill Hospital, Oxford, UK

R. R. Holman • J. C. Levy

NIHR Oxford Biomedical Research Centre, University of Oxford, Oxford, UK

Present address:

U. Ayyagari

Mumbai, India
}

and fasting glucose on diet alone of 10.6 (2.9) $\mathrm{mmol} / \mathrm{l}$; while those in the descending glucose steps group $(n=9)$ had mean age of $58.2(8.0)$ years, BMI of $30.5(5.4) \mathrm{kg} / \mathrm{m}^{2}$ and fasting glucose on diet alone of $9.8(2.2) \mathrm{mmol} / \mathrm{l}$. The geometric means $(95 \% \mathrm{CI})$ of C-peptide secretion rates on placebo for glucose at $4.0,8.0$ and $12.0 \mathrm{mmol} / \mathrm{l}$ were $63(46,86), 143(105,195)$ and $205(149,281) \mathrm{pmol} / \mathrm{min}$, respectively. On glibenclamide, this increased by $140(99,181), 126(85,167)$ and $158(117,199)$ $\mathrm{pmol} / \mathrm{min}$, respectively ( $p<0.001$ vs placebo). The absolute increment was significant $(p<0.001)$ and independent of clamp glucose concentration $(p=0.54)$. The proportional increase was greater at $4 \mathrm{mmol} / \mathrm{l}: 2.8$-fold $(2.4,3.2)$, compared with 1.8 -fold $(1.5,2.0)$ and 1.7 -fold $(1.4,1.9)$ at 8 and $12 \mathrm{mmol} / \mathrm{l}$, respectively $(p<0.001)$.

Conclusions/interpretation At low-normal glucose, glibenclamide exerted a disproportionate effect on insulin secretion. This study highlights the risks of hypoglycaemia when aiming for tight glucose control on this agent.

Keywords C-peptide secretion · Glibenclamide · Glyburide • Insulin secretion · Sulfonylurea · Type 2 diabetes

\begin{tabular}{|c|c|}
\hline Abbreviations & \\
\hline CPSR & C-peptide secretion rate \\
\hline HOMA2_\%B & $\begin{array}{l}\text { HOMA2 estimate of pancreatic beta cell } \\
\text { function }\end{array}$ \\
\hline HOMA2_\%S & HOMA2 estimate of insulin sensitivity \\
\hline
\end{tabular}

Introduction

Current guidelines recommend metformin as a first-line treatment of raised plasma glucose in type 2 diabetes, with early addition of second-line sulfonylurea, if required, to achieve glycaemic control [1]. Sulfonylureas act by increasing insulin 
secretion by pancreatic beta cells without affecting peripheral insulin sensitivity [2-5]. Perhaps the most important adverse effect of sulfonylurea therapy is the development of hypoglycaemia, though different sulfonylureas may vary in the degree to which they cause this [6-9]. The rates of hypoglycaemia in patients on sulfonylurea therapy can be comparable to those on insulin $[10,11]$. In view of this, there may be an argument to opt for newer therapeutic agents with lower rates of hypoglycaemia earlier in the treatment algorithm.

While the in vivo effects of sulfonylureas have been studied in patients with type 2 diabetes at supra-physiological glucose concentrations, only one in vivo study has been conducted to evaluate the contribution of sulfonylureas to hyperinsulinaemia at low or low-normal glucose concentrations [12]. The aim of the present study was to explore the mechanism of hypoglycaemic action of glibenclamide by determining its effects on the incremental and proportional insulin secretion rate assessed at low, elevated and high blood glucose levels in patients with type 2 diabetes.

\section{Methods}

Participants Patients with type 2 diabetes mellitus treated with diet alone or metformin, with or without a low dose sulfonylurea, were recruited from January to November 1995. Participants were included if their fasting plasma glucose was less than $11 \mathrm{mmol} / \mathrm{l}$ on diet treatment alone, or having stopped a low dose of sulfonylurea. They were excluded if they suffered from active cardiac disease, severe diabetic complications or other major illnesses. Participants were randomly allocated to one of two groups who received either ascending or descending glucose clamp levels, using minimisation on standardised Mahalanobis distances to match the groups for sex, BMI and 7-day mean fasting blood glucose. Participants stopped oral glucose-lowering medications for 3 weeks prior to the study to ensure complete washout of their effects. All participants were on a weight-maintaining diet and were asked not to change their dietary habits during the study. The success of this was not verified by food diaries, however. All participants gave their written informed consent. The study was approved by the Central Oxford Ethics Committee.

Study design The study was a randomised, double-blind, placebo-controlled, crossover study. Participants received 14 days treatment with glibenclamide ( $2.5 \mathrm{mg}$ twice daily) and placebo in random order, with a washout period of at least 14 days with no additional glucose-lowering medication treatment periods. A three-step hyperinsulinaemic glucose clamp was performed at the end of each treatment period, with plasma glucose clamped at 4.0, 8.0 and $12.0 \mathrm{mmol} / \mathrm{l}$ using a fixed rate insulin infusion and a variable rate glucose infusion. Plasma C-peptide concentration was measured at intervals and deconvoluted to estimate C-peptide (and hence insulin) secretion rates.

Hyperinsulinaemic three-step ascending and descending clamp procedure Participants were admitted to the Diabetes Trials Unit clinical research facility at 7:30 am on two separate mornings after an overnight fast, apart from water to drink. A concentric double-lumen Teflon cannula was inserted into a wrist vein. The hand was warmed with an electric heating pad at $47^{\circ} \mathrm{C}$ to arterialise the venous blood. A second cannula was placed in an antecubital vein for glucose and insulin infusion. Heparinised blood was withdrawn continuously throughout the clamp using a peristaltic pump and fraction collector. Three integrated 6 min samples were taken, following which participants took either the glibenclamide $2.5 \mathrm{mg}$ or placebo tablets that they had been taking the previous 14 mornings.

At time 0 and $30 \mathrm{~min}$ after taking the tablets, an insulin infusion was started at an initial priming rate of $480 \mathrm{mU} \mathrm{m}^{-2} \mathrm{~min}^{-1}$ for $10 \mathrm{~min}$, then reduced to $80 \mathrm{mU} \mathrm{m}^{-2} \mathrm{~min}^{-1}$ for the rest of the procedure [13]. The prime and the sustained insulin infusion rates were double those described in the original report of the hyperinsulinaemic clamp to ensure that a blood glucose concentration of $4 \mathrm{mmol} / \mathrm{l}$ would be achieved in these overweight or obese patients with a mean HOMA2 insulin sensitivity [\%S] (www.dtu.ox.ac.uk/ homacalculator/, last accessed 17 September 2014) of approximately $50 \%$. The glucose infusion rate was adjusted to achieve and maintain each of the targeted blood glucose levels. Successive $3 \mathrm{~min}$ blood glucose results were entered into an iterative computer program that used current and previous glucose concentrations and glucose infusion rates to recommend a glucose infusion rate appropriate to maintain desired levels of glycaemia [14]. Ascending stepped changes in blood glucose were achieved with boluses of $25 \%$ glucose diluted in normal saline, as recommended by the computer program.

Both ascending and descending clamp orders were used and were studied in the parallel groups to account for the possibility that the insulin secretory response to glucose could differ in conditions of rising or falling glucose concentrations and could be influenced by antecedent glucose concentrations during the investigative procedure.

For ascending clamps, blood glucose was stabilised at $4 \mathrm{mmol} / \mathrm{l}$ over the first $120 \mathrm{~min}$. The blood glucose was then raised acutely to $8 \mathrm{mmol} / \mathrm{l}$ and clamped at this level until $210 \mathrm{~min}$. The blood glucose was then again raised acutely to $12 \mathrm{mmol} / \mathrm{l}$ and clamped at this level until $300 \mathrm{~min}$.

For descending clamps, blood glucose was initially raised at time 0 to $12 \mathrm{mmol} / \mathrm{l}$ by glucose bolus injection. The blood glucose was clamped at this level until $120 \mathrm{~min}$. The blood glucose was then allowed to fall and clamped at $8 \mathrm{mmol} / \mathrm{l}$ until $210 \mathrm{~min}$. The blood glucose was then again allowed to fall and clamped at $4 \mathrm{mmol} / \mathrm{l}$ until $300 \mathrm{~min}$. 
At the end of the study, participants were provided with lunch and the glucose infusion was maintained as required until blood glucose levels were rising or stable for at least 15 min without glucose infusion.

Assays A rapid glucose oxidase method (Hemocue B Glucose Photometer; Hemocue AB, Ängelholm, Sweden) was used to measure glucose concentration every 3 min during the clamps. Integrated 6 min plasma samples (pooled samples from two $3 \mathrm{~min}$ aliquots) were also assayed by a laboratory hexokinase method (Boehringer Mannheim, Lewes, UK).

Fasting insulin was measured using a double antibody RIA (Pharmacia, Milton Keynes, UK) with Sepharose attached to the second antibody for separation by decanting. Human insulin standard was calibrated against 'Research Standard A for insulin, human, for immunoassay 66/304' from WHO International Laboratory for Biological Standards.

Plasma C-peptide was assayed on each 6 min pooled aliquot by RIA (Linco, Biogenesis, Poole, UK), using a competitive, equilibrium RIA using ${ }^{125}$ I-labelled human C-peptide with guinea pig anti-human C-peptide antibody and polyethylene glycol precipitation.

Calculations The C-peptide secretion rate (CPSR) was calculated from the plasma C-peptide concentration in 6 min aliquots of blood that was continuously withdrawn throughout the clamp procedure. The mean CPSR at the end of each clamp stage was calculated by taking the arithmetic mean of the five values covering the final $30 \mathrm{~min}$ of each clamp stage (90-120, 180-210 and 270-300 min from the start of the clamp). Similarly, the plasma glucose concentration was calculated for each participant as the mean of the five calculated secretion rates during the last $30 \mathrm{~min}$ of each clamp stage. The first phase response to a $4 \mathrm{mmol} / \mathrm{l}$ step increase in plasma glucose was calculated for the $4 \mathrm{mmol} / \mathrm{l}$ to $8 \mathrm{mmol} / \mathrm{l}$ and $8 \mathrm{mmol} / 1$ to $12 \mathrm{mmol} / 1$ transitions in the ascending clamp group. This was calculated as the difference between mean CPSR of the first three values after the step-up points (120-138 and 210-228 min) and the CPSR during the last $30 \mathrm{~min}$ at the end of the preceding clamp stage (as detailed above).

Modelling analysis The HOMA2 computer model of the homeostatic basal insulin:glucose interaction was used to assess the contribution of two variables, beta cell function (HOMA2 \%B) and insulin sensitivity (HOMA2 \%S), to the fasting glucose and insulin or C-peptide concentrations [15]. HOMA2 [16] is calibrated to a reference population of normal weight healthy individuals aged $<35$ years who were defined as having 'normal' values of $\% \mathrm{~B}$ and $\% \mathrm{~S}$ equal to $100 \%$. Three consecutive 6 min blood samples were withdrawn continuously from $-50,-44$ and -38 min for measurement of plasma glucose, insulin and C-peptide. HOMA2_\%S was determined from glucose-insulin pairs and HOMA2_\%B from glucose-C-peptide pairs.

Beta cell stimulus-response curve assessed by CPSR The two-compartment model and deconvolution equations of Eaton et al were used to calculate estimates of insulin secretion rates from plasma C-peptide concentrations [17]. The variables of the model were derived from Van Cauter's adjusted population values taking into account sex, age, obesity and diabetic status of the individual participants [18].

Statistical analysis Data were collected on clinical report forms and double entry was performed and stored in a readonly file on the departmental server blind to randomisation codes. Non-parametric variables were transformed logarithmically. These included fasting plasma insulin, HOMA2 $\%$ B and HOMA2_\%S indices, CPSRs and their proportional increments on glibenclamide. Second phase CPSR and the incremental impact of glibenclamide between treatment periods were compared using ANOVA with treatment order, treatment, ascending vs descending clamp order and clamp glucose steps as fixed factors. Pairwise comparisons were performed using Dunnett's test. Statistical analyses were performed using SPSS for Windows, Rel. 18.0.0 (IBM, Portsmouth, UK). Descriptive statistics are expressed either as mean (1 SD) for symmetrical distributions, or geometric mean (SD range) for positively skewed distributions. Statistical estimates are expressed either as mean or geometric mean $(95 \% \mathrm{CI})$. Geometric mean and error bars for SEM range are presented in Figs 1 and 2.

\section{Results}

Twenty-two patients with type 2 diabetes were randomised. One patient in the ascending clamp group and two patients in the descending clamp group did not complete the study so ten patients in the ascending and nine patients in the descending clamp groups had analysable data sets. At the time of recruitment, in the ascending arm group, five, three and two patients were on diet alone, sulfonylurea alone and metformin alone, respectively; and on the descending arm, six, three and no patients were on diet alone, sulfonylurea alone and metformin alone, respectively ( $p=0.36$ between groups). Demographic details when studied on placebo alone are shown in Table 1. Treatment with glibenclamide for 14 days reduced fasting blood glucose by $2.3 \mathrm{mmol} / \mathrm{l}$ and increased beta cell function as measured by HOMA2 analysis (HOMA2 \%B), but did not significantly change body weight, plasma insulin or insulin sensitivity (HOMA2_\%S; Table 2).

Second phase C-peptide and CPSR during stepped glucose clamps Achieved blood glucose at the end of each clamp 
Fig. 1 Mean (SEM) whole blood glucose $(\mathbf{a}, \mathbf{c})$ and geometric mean (SEM range) CPSRs (b, d) for ascending (a, b) and descending (c, d) clamp protocols; placebotreated (black diamonds) and glibenclamide-treated $(2.5 \mathrm{mg}$ twice daily) (open triangles). The dashed vertical lines represent the start of the phases of the clamp (4, 8 and $12 \mathrm{mmol} / \mathrm{l}$ for ascending clamps and 12, 8 and $4 \mathrm{mmol} / \mathrm{l}$ for the descending clamps) a

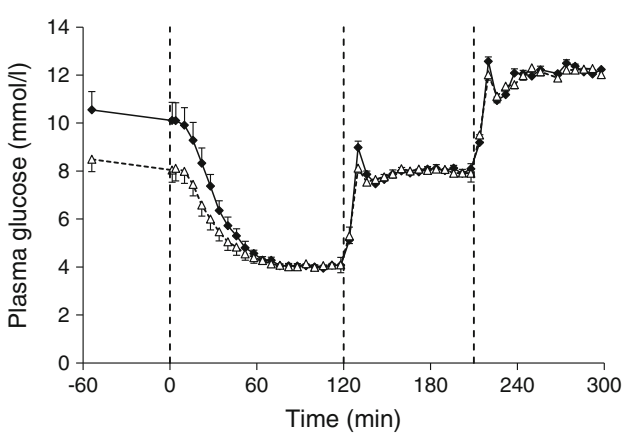

C

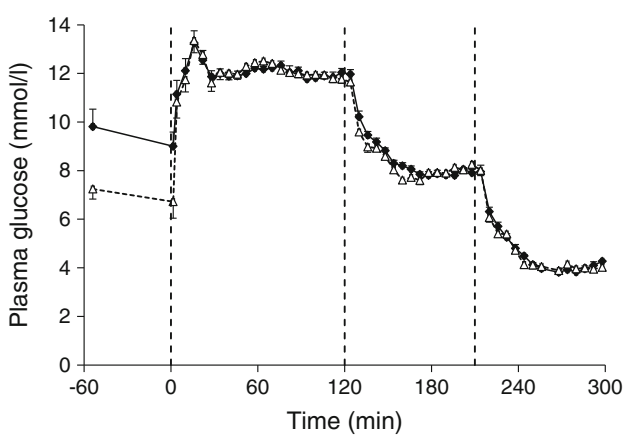

b

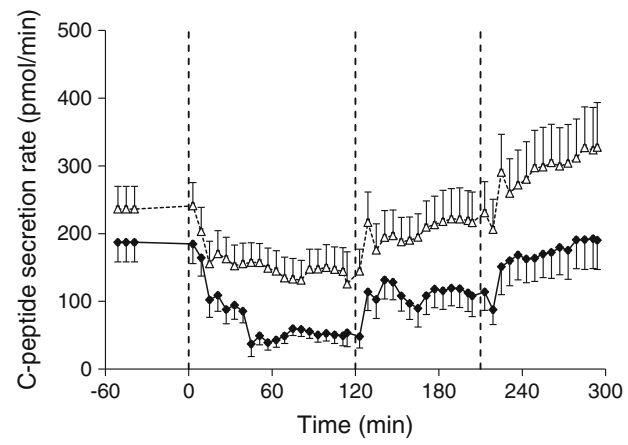

d

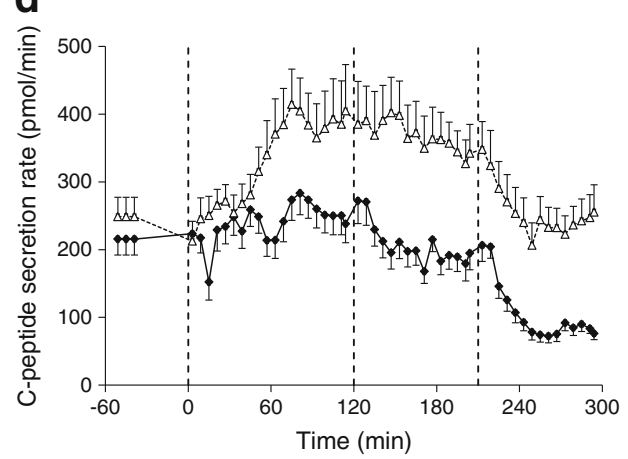

stage were mean (1 SD) $4.0(0.2), 8.0(0.2)$ and $12.0(0.3)$ $\mathrm{mmol} / \mathrm{l}$. Plasma C-peptide concentrations at the three clamp levels in the amalgamated groups are shown in Table 3. Blood glucose profiles and calculated CPSR are shown during ascending and descending stepped clamps in Fig. 1. Treatment order did not affect C-peptide or CPSR ( $p=0.94)$.

The mean C-peptide concentration and CPSR increased with each of the three glucose clamp levels $(p<0.001)$ and was greater for the descending compared with the ascending clamp order $(p=0.004)$. However, there was no interaction between clamp glucose concentrations and clamp order, so

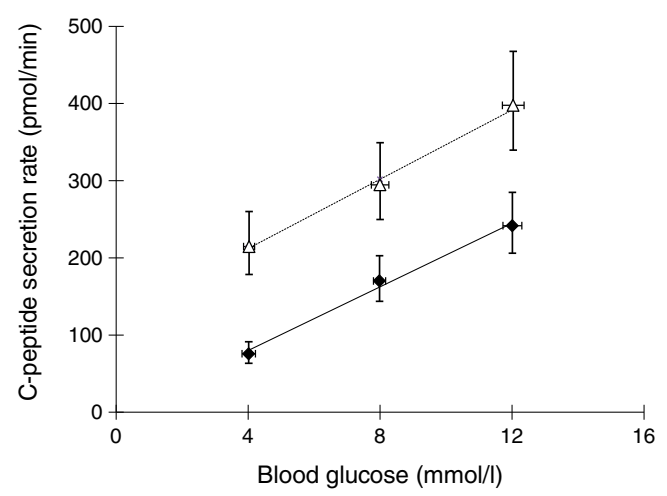

Fig. 2 Average CPSRs in 19 patients with type 2 diabetes during the last 30 min of each clamp step, following 14 days' treatment with either placebo (black diamonds and solid line) or glibenclamide $2.5 \mathrm{mg}$ twice daily (open triangles and dotted line). Symbols represent geometric means and vertical and horizontal bars are 1 SEM range. Lines represent best fit linear regression estimates mean values are presented in Tables 2 and 3 and in Figs 1 and 2. The absolute incremental impact of glibenclamide was similar at each blood glucose concentration $(p=0.54)$, but was greater in the descending compared with the ascending clamps at each clamp level $(p=0.011)$. The estimated marginal means are presented for both groups combined in Table 3 and Fig. 2 . However, the proportional increment was associated with clamp glucose level $(p<0.001)$ and was significantly greater at the $4 \mathrm{mmol} / \mathrm{l} \mathrm{clamp} \mathrm{step} \mathrm{than} \mathrm{at} \mathrm{the} 8$ and the $12 \mathrm{mmol} / \mathrm{l}$ steps (both $p<0.001$ ), while the proportional responses at 8 and $12 \mathrm{mmol} / \mathrm{l}$ did not differ from each other ( $p=0.78$; Table 3$)$.

First phase CPSR during stepped glucose clamps The first phase responses to the step up in glucose from 4 to 8 and from 8 to $12 \mathrm{mmol} / \mathrm{l}$ were calculated for the ascending glucose clamps and analysed with respect to glucose clamp level and treatment. There were no significant differences in the first phase responses to the $4 \mathrm{mmol} / \mathrm{l}$ rise in clamp glucose levels between the $4 \mathrm{mmol} / \mathrm{l}$ and $8 \mathrm{mmol} / \mathrm{l}$ clamp stages or between placebo and glibenclamide treatments $(p=0.23$ and $p=0.61$, respectively).

\section{Discussion}

We have demonstrated that there was no diminution of the absolute incremental effect of glibenclamide on second phase 
Table 1 Characteristics of participants on placebo alone

Data are means (1 SD)

${ }^{\text {a }}$ Independent samples, Student's $t$ test

${ }^{\mathrm{b}}$ Pearson's $\chi^{2}$ test

\begin{tabular}{llll}
\hline Characteristic & Ascending clamp order & Descending clamp order & $p$ value \\
\hline Number of participants & 10 & 9 & \\
Age (years) & $60.3(6.5)$ & $58.2(8.0)$ & $0.54^{\mathrm{a}}$ \\
Sex (M:F) & $5: 5$ & $5: 4$ & $0.81^{\mathrm{b}}$ \\
BMI $\left(\mathrm{kg} / \mathrm{m}^{2}\right)$ & $29.8(4.9)$ & $30.5(5.4)$ & $0.78^{\mathrm{a}}$ \\
Fasting plasma glucose $(\mathrm{mmol} / \mathrm{l})$ & $10.6(2.9)$ & $9.8(2.2)$ & $0.54^{\mathrm{a}}$ \\
\hline
\end{tabular}

CPSRs at lower blood glucose levels. However, the threefold proportional increase in CPSR was greater at $4 \mathrm{mmol} / \mathrm{l}$, compared with the approximately twofold increases at 8 and $12 \mathrm{mmol} / 1$.

The strengths of this study include the use of a hyperinsulinaemic clamp design to investigate the effect of glibenclamide on insulin secretion in type 2 diabetes at low, moderately raised and clearly raised plasma glucose concentrations relevant to the clinical situation experienced by a patient with type 2 diabetes. Stepped hyperglycaemic clamp protocols directed at the hyperglycaemic state are usually conducted as successive increases in plasma glucose steps, while those directed at the hypoglycaemia state usually follow the reverse order. However, sustained clamped hyperglycaemia is associated with a steady rise of insulin secretion so that a descending step protocol may overestimate insulin secretion at later, lower plasma glucose concentrations. To minimise these potential sources of bias, we studied the effects of both rising and falling plasma glucose steps in parallel groups and estimated order effects in the analysis.

While others have investigated the action of sulfonylureas at higher blood glucose concentrations, the use of a hyperinsulinaemic clamp protocol in the present study allowed us to study what would constitute a low glucose concentration for a patient requiring a glucose-lowering drug.

Table 2 Impact of 14 days glibenclamide ( $2.5 \mathrm{mg}$ twice daily) on fasting plasma glucose and insulin, beta cell function and insulin sensitivity

\begin{tabular}{llll}
\hline & Placebo & Glibenclamide & $p$ value $^{\mathrm{a}}$ \\
\hline $\begin{array}{l}\text { Number of participants } \\
\text { Body weight }(\mathrm{kg})^{\mathrm{b}}\end{array}$ & 19 & 19 & - \\
$\begin{array}{l}\text { Fasting plasma glucose } \\
\left(\mathrm{mmol} / \mathrm{l}^{\mathrm{b}}\right.\end{array}$ & $10.2(9.2,11.2)$ & $7.9(6.9,8.9)$ & 0.002 \\
$\begin{array}{c}\text { Fasting plasma insulin } \\
(\mathrm{pmol} / \mathrm{l})^{\mathrm{c}}\end{array}$ & $109(82,144)$ & $121(91,161)$ & 0.58 \\
$\begin{array}{l}\text { HOMA2\%\%B } \\
\text { HOMA2_\% }\end{array}$ & $41(30,55)$ & $70(52,96)$ & 0.016 \\
\hline
\end{tabular}

${ }^{a}$ Estimated marginal means from ANOVA with treatment as the fixed factor

${ }^{\mathrm{b}}$ Mean $(95 \% \mathrm{CI})$

${ }^{\mathrm{c}}$ Geometric mean $(95 \% \mathrm{CI})$
Hosker et al investigated the effect of glibenclamide and chlorpropamide on insulin secretion at a plasma glucose of 11 and $13 \mathrm{mmol} / \mathrm{l}$ and found an approximate doubling of insulin secretion at each of these concentrations, closely matching the results we have shown here [19]. Groop et al showed a tendency for an additive effect on second phase insulin secretion in patients with type 2 diabetes at glucose levels ranging from 10 to $25 \mathrm{mmol} / \mathrm{l}$ [20]. Ligtenberg et al showed stimulation of insulin secretion by glibenclamide at $8 \mathrm{mmol} / \mathrm{l}$ blood glucose level during hyperglycaemic clamps [21]. Their use of hyperglycaemic clamps, however, precluded the assessment of effects at lower glucose concentrations. During post-hyperglycaemic clamp observation periods in patients on sulfonylureas, Abbink et al demonstrated that rates of insulin secretion respond poorly to decreasing glucose levels, with an increase in the number of hypoglycaemic events [22]. These suggested effects of sulfonylurea therapy are in agreement with our results at low-normal glucose concentrations. The present study is relevant particularly in the context of the recognised hypoglycaemic risk in patients with type 2 diabetes on oral therapy [11].

To investigate carbohydrate metabolism at blood glucose concentrations below a person's normal fasting values, an exogenous insulin infusion is required. It is not possible to measure endogenous insulin concentration using human insulin infusions. As C-peptide is co-secreted with insulin in an equimolar ratio, is not extracted by the liver and has a constant peripheral clearance, we assessed CPSRs by deconvolution of C-peptide concentrations using the two-compartment model of Eaton, and estimating kinetic variables by the method of van Cauter et al [18].

The weaknesses of this study include the relatively small number of participants and the lack of direct evidence to exclude the negative feedback of infused insulin on endogenous secretion. While the number of participants was relatively small, the crossover design meant that this was sufficient to demonstrate significant differences between the two treatment modalities at the three clamp glucose concentrations while accommodating the ascending and descending clamp protocol in the analysis.

Experimental lowering of plasma glucose below the homeostatic level requires exogenous insulin infusion and therefore a state of hyperinsulinaemia. This is unavoidable, but 
Table 3 Average C-peptide concentration and $\mathrm{CPSR}^{\mathrm{a}}$ during the last 30 min of each clamp stage following 14 days placebo treatment, and absolute and proportional increments following 14 days glibenclamide treatment ${ }^{\mathrm{b}}$

\begin{tabular}{|c|c|c|c|c|}
\hline Clamp glucose level & $4 \mathrm{mmol} / \mathrm{l}$ & $8 \mathrm{mmol} / \mathrm{l}$ & $12 \mathrm{mmol} / \mathrm{l}$ & $\begin{array}{l}\text { Overall } p \text { value between } \\
\text { glucose levels }\end{array}$ \\
\hline Plasma C-peptide concentration on placebo & $0.35(0.27,0.46)$ & $0.56(0.42,0.73)$ & $0.74(0.56,0.97)$ & 0.001 \\
\hline Plasma C-peptide concentration on glibenclamide** & $0.77(0.59,1.02)$ & $0.97(0.73,1.27)$ & $1.18(0.89,1.55)$ & 0.104 \\
\hline CPSR on placebo** & $63(46,86)$ & $143(105,195)$ & $205(149,281)$ & $<0.001$ \\
\hline Absolute increment in CPSR on glibenclamide ${ }^{c}$ & $140(99,181)$ & $126(85,167)$ & $158(117,199)$ & 0.54 \\
\hline Proportional increment on glibenclamide ${ }^{c}$ & $2.8(2.4,3.2)$ & $1.8^{\dagger \dagger \dagger}(1.5,2.0)$ & $1.7^{\dagger \dagger, \ddagger}(1.4,1.9)$ & $<0.001$ \\
\hline
\end{tabular}

Data are shown as means $(95 \% \mathrm{CI})$, unless otherwise stated

${ }^{a} \mathrm{C}$-peptide concentrations and CPSR were measured in $\mathrm{nmol} / \mathrm{ml}$ and $\mathrm{pmol} / \mathrm{min}$, respectively

${ }^{\mathrm{b}}$ Estimated marginal means from ANOVA with clamp type as the fixed factor and clamp glucose as a covariate

${ }^{\mathrm{c}}$ Geometric mean $(95 \% \mathrm{CI})$

$* * p=0.004$ for mean difference between ascending and descending clamp types

${ }^{\dagger \dagger} p=0.001$ vs $4 \mathrm{mmol} / 1$ clamp glucose level (Dunnett's Test)

${ }^{\ddagger} p=0.78$ vs $8 \mathrm{mmol} / \mathrm{l}$ clamp glucose level (Dunnett's Test)

unphysiological, the more so when homeostatic insulin concentrations are relatively low, such as in insulin sensitive individuals or those treated with metformin. Glucose clamping is an experimental technique that deliberately uncouples the glucose-insulin feedback system and thereby is necessarily unphysiological. However, no other technique allows the direct measurement of insulin secretory responses that otherwise would have to be estimated using mathematical modelling. Exogenous hyperinsulinaemia also presents the potential problem that insulin has been shown to have an inhibitory effect on its own secretion in vitro. Existing data as to whether this is significant in vivo is conflicting, with inhibition being found in some studies, but not in others [23-26]. While an inhibitory effect may lead to an underestimation of the secretory responses, the same insulin infusion rates were used in both the placebo and treatment arms in the current study and so would not be expected to affect the comparison between them. Moreover, the degree of pancreatic stimulation seen in our study was similar to that seen in other studies $[19,20]$.

Sulfonylureas are recognised as being associated with hypoglycaemia. Between 13 and $21 \%$ of patients on sulfonylureas report episodes of hypoglycaemia, and the prevalence of major hypoglycaemia (defined as needing third party assistance) is $0.5-2.5 \%$ episodes per person year $[11,27]$. In the UK Hypoglycaemia Study, patients with type 2 diabetes on either sulfonylurea therapy or insulin treatment reported a similar incidence of episodes of severe hypoglycaemia. When a sulfonylurea is prescribed in combination therapy with metformin, thiazolidinedione, gliptin or a glucagon-like peptide-1 (GLP-1) agonist, the incidence of hypoglycaemia increases two- to threefold [11]. Current guidelines recommend early, multi-factorial risk reduction in type 2 diabetes to improve long-term metabolic outcomes. This is especially true for glycaemic targets, as the benefit of tight glycaemic control, especially early on in the course of type 2 diabetes, is well established $[28,29]$. Therapy with multiple glucose-lowering agents is frequently required to meet the recommended tight $\mathrm{HbA}_{1 \mathrm{c}}$ targets, and the recommendation for sulfonylureas, used either as a first- or second-line agent, in treatment algorithms, is standard [30]. Our data illustrate the problem with this recommendation. Sulfonylureas enhance insulin secretion by residual beta cell function, which declines progressively with duration of type 2 diabetes; therefore, it could be argued that the best role for sulfonylureas would be early in the disease spectrum, where they may be thought to offer the maximum benefit. However, because of the disproportionate stimulation of insulin secretion at low glucose concentrations shown in this study, this group would be the most vulnerable to the risk of hypoglycaemia, especially when aiming for tight glycaemic control.

In conclusion, we have demonstrated that the obligatory and disproportionate stimulatory effect of glibenclamide on insulin secretion at low glucose levels reflects the mechanism of action of this modality of therapy and underlies its known tendency to produce hypoglycaemia, particularly early in the course of type 2 diabetes. This emphasises the need for cautious titration when using sulfonylureas as second-line agents after metformin when attempting to maintain tight glucose control.

Acknowledgements We would like to thank I. Stratton (Gloucestershire Diabetic Retinopathy Research Group, Gloucester, UK) for power calculations; B. Barrow, N. Walraevens and C. Dudley for nursing support, and P. Sutton for supervision of immunoassays (Diabetes Trials Unit, Oxford UK). The research was supported by the National Institute for Health Research (NIHR) Oxford Biomedical Research Centre based at Oxford University Hospitals NHS Trust and University of Oxford. The views expressed are those of the authors and not necessarily those of the NHS, the NIHR or the Department of Health. 
Funding This study was supported by a grant from Knoll Pharmaceuticals.

Duality of interest The authors declare that there is no duality of interest associated with this manuscript.

Contributions AR contributed substantially to the acquisition of the data, and drafting and revising the article. UA contributed to interpreting the study, and drafting and revising the article. SEM contributed to the acquisition of the data and revising the article. RRH made substantial contributions to the conception of the study and obtaining funding, and to revising the article. JCL made substantial contributions to the conception, design and interpretation of the study, analysed the data, drafted and revised the article, and is responsible for the integrity of the work as a whole. All authors gave their final approval of the version of the article to be published.

\section{References}

1. Inzucchi SE, Bergenstal RM, Buse JB et al (2012) Management of hyperglycemia in type 2 diabetes: a patient-centered approach: position statement of the American Diabetes Association (ADA) and the European Association for the Study of Diabetes (EASD). Diabetes Care 35:1364-1379

2. Gerich JE (1989) Oral hypoglycemic agents. N Engl J Med 321:1231-1245

3. Groop LC (1992) Sulfonylureas in NIDDM. Diabetes Care 15:737-754

4. Gutniak M, Karlander SG, Efendic S (1987) Glyburide decreases insulin requirement, increases beta-cell response to mixed meal, and does not affect insulin sensitivity: effects of short- and long-term combined treatment in secondary failure to sulfonylurea. Diabetes Care 10:545-554

5. Gylfe E, Hellman B, Sehlin J, Taljedal B (1984) Interaction of sulfonylurea with the pancreatic B cell. Experientia 40:1126-1134

6. UKPDS Group (1995) United Kingdom Prospective Diabetes Study (UKPDS). 13: Relative efficacy of randomly allocated diet, sulphonylurea, insulin, or metformin in patients with newly diagnosed non-insulin dependent diabetes followed for three years. BMJ 310:83-88

7. Berger W (1985) Incidence of severe side effects during therapy with sulfonylureas and biguanides. Horm Metab Res Suppl 15:111-115

8. Holstein A, Plaschke A, Egberts EH (2001) Lower incidence of severe hypoglycaemia in patients with type 2 diabetes treated with glimepiride versus glibenclamide. Diabetes Metab Res Rev 17:467-473

9. Wright AD, Cull CA, Macleod KM, Holman RR (2006) Hypoglycemia in type 2 diabetic patients randomized to and maintained on monotherapy with diet, sulfonylurea, metformin, or insulin for 6 years from diagnosis: UKPDS73. J Diabetes Complications 20:395-401

10. Gangii AS, Cukierman T, Gerstein HC, Goldsmith $\mathrm{CH}$, Clase CM (2007) A systematic review and meta-analysis of hypoglycemia and cardiovascular events: a comparison of glyburide with other secretagogues and with insulin. Diabetes Care 30:389-394

11. UK Hypoglycaemia Study Group (2007) Risk of hypoglycaemia in types 1 and 2 diabetes: effects of treatment modalities and their duration. Diabetologia 50:1140-1147

12. Aldhahi W, Armstrong J, Bouche C, Carr RD, Moses A, Goldfine $\mathrm{AB}$ (2004) Beta-cell insulin secretory response to oral hypoglycemic agents is blunted in humans in vivo during moderate hypoglycemia. J Clin Endocrinol Metab 89:4553-4557
13. Hovorka R, Powrie JK, Jones RH (1994) A simulation study to determine optimal insulin priming during glucose clamp studies. Comput Methods Programs Biomed 41:231-241

14. Matthews DR, Edge JA, Dunger DB (1990) An unbiased glucose clamp method using a variable insulin infusion: its application in diabetic adolescents. Diabet Med 7:246-251

15. Matthews DR, Hosker JP, Rudenski AS, Naylor BA, Treacher DF, Turner RC (1985) Homeostasis model assessment: insulin resistance and beta-cell function from fasting plasma glucose and insulin concentrations in man. Diabetologia 28:412-419

16. Wallace TM, Levy JC, Matthews DR (2004) Use and abuse of HOMA modeling. Diabetes Care 27:1487-1495

17. Eaton RP, Allen RC, Schade DS, Erickson KM, Standefer J (1980) Prehepatic insulin production in man: kinetic analysis using peripheral connecting peptide behavior. J Clin Endocrinol Metab 51:520-528

18. Van Cauter E, Mestrez F, Sturis J, Polonsky KS (1992) Estimation of insulin secretion rates from C-peptide levels. Comparison of individual and standard kinetic parameters for C-peptide clearance. Diabetes 41:368-377

19. Hosker JP, Burnett MA, Davies EG, Harris EA, Turner RC (1985) Sulphonylurea therapy doubles B cell response to glucose in type 2 diabetic patients. Diabetologia 28:809-814

20. Groop L, Groop PH, Stenman S et al (1987) Comparison of pharmacokinetics, metabolic effects and mechanisms of action of glyburide and glipizide during long-term treatment. Diabetes Care 10:671-678

21. Ligtenberg JJ, Venker CE, Sluiter WJ, Reitsma WD, van Haeften TW (1997) Effect of glibenclamide on insulin release at moderate and high blood glucose levels in normal man. Eur J Clin Invest 27:685-689

22. Abbink EJ, van der Wal PS, Sweep CG, Smits P, Tack CJ (2004) Compared to glibenclamide, repaglinide treatment results in a more rapid fall in glucose level and beta-cell secretion after glucose stimulation. Diabetes Metab Res Rev 20:466-471

23. Elahi D, Nagulesparan M, Hershcopf RJ et al (1982) Feedback inhibition of insulin secretion by insulin: relation to the hyperinsulinemia of obesity. N Engl J Med 306:1196-1202

24. Kraegen EW, Lazarus L, Campbell LV (1983) Failure of insulin infusion during euglycemia to influence endogenous basal insulin secretion. Metabolism 32:622-627

25. Shima K, Morishta S, Sawazaki N, Tanaka R, Tarui S (1977) Failure of exogenous insulin to inhibit insulin secretion in man. Horm Metab Res 9:441-443

26. Waldhausl WK, Gasic S, Bratusch-Marrain P, Korn A, Nowotny P (1982) Feedback inhibition by biosynthetic human insulin of insulin release in healthy human subjects. Am J Physiol 243:E476-E482

27. Matthews DR, Cull CA, Stratton IM, Holman RR, Turner RC (1998) United Kingdom Prospective Diabetes Study (UKPDS) 26: sulphonylurea failure in non-insulin-dependent diabetic patients over six years. Diabet Med 15:297-303

28. Gaede P, Lund-Andersen H, Parving HH, Pedersen O (2008) Effect of a multifactorial intervention on mortality in type 2 diabetes. $\mathrm{N}$ Engl J Med 358:580-591

29. Holman RR, Paul SK, Bethel MA, Matthews DR, Neil HA (2008) 10 -year follow-up of intensive glucose control in type 2 diabetes. N Engl J Med 359:1577-1589

30. Nathan DM, Buse JB, Davidson MB et al (2009) Medical management of hyperglycemia in type 2 diabetes: a consensus algorithm for the initiation and adjustment of therapy: a consensus statement of the American Diabetes Association and the European Association for the Study of Diabetes. Diabetes Care 32:193-203 